\title{
Environmental suitability for Lutzomyia (Nyssomyia) whitmani (Diptera: Psychodidae: Phlebotominae) and the occurrence of American cutaneous leishmaniasis in Brazil
}

Simone Miranda da Costa $^{1 *}$, José Luís Passos Cordeiro ${ }^{2}$ and Elizabeth Ferreira Rangel ${ }^{1}$

\begin{abstract}
Background: Leishmaniasis represents an important public health problem in Brazil. The continuous process of urbanization and expansion of human activities in forest areas impacts natural habitats, modifying the ecology of some species of Leishmania, as well as its vectors and reservoirs and, consequently, changes the epidemiological pattern that contributes to the expansion of American cutaneous leishmaniasis in Brazil. Here, we discuss Lutzomyia (Nyssomyia) whitmani, the main vector of ACL, transmitting two dermotropic Leishmania species including Leishmania (Viannia) braziliensis and Leishmania (V.) shawi.
\end{abstract}

Methods: We used the maximum entropy niche modelling approach (MaxEnt) to evaluate the environmental suitability of $L$. (N.) whitmani and the transmission of ACL in Brazil, in addition to designing models for a future scenario of climate change. MaxEnt was used under the "auto-features" mode and the default settings, with 100-fold repetition (bootstrap). The logistic output was used with higher values in the habitat suitability map, representing more favourable conditions for the occurrence of $L$. (N.) whitmani and human cases of ACL.

Results: Two models were developed: the Lutzomyia (N.) whitmani model (LWM) and the American cutaneous leishmaniasis model (ACLM). LWM identified the species "preferential habitat" included regions with moderate annual precipitation (AP) between 1000-1600 mm, intermediate vegetation density (NDVI) values, mean temperature of the coldest quarter (MTCQ), between $15-21^{\circ} \mathrm{C}$, and annual mean temperature (AMT), between $19-24^{\circ} \mathrm{C}$. ACLM indicates that $\mathrm{ACL}$ is strongly associated with areas of intermediate density vegetation, areas with AP between $800-1200 \mathrm{~mm}$, MTCQ above $16{ }^{\circ} \mathrm{C}$ and AMT below $23^{\circ} \mathrm{C}$.

Conclusions: The models generated for $L$. (N.) whitmani and ACL indicated a satisfactory predictive capacity. Future projections of LWM indicate an expansion of climatic suitability for L. (N.) whitmani for the northern and southern regions of Brazil. Future projections of $A C L$ indicate the ongoing process of disease expansion in the face of the predicted climatic changes and reinforce the broad geographical expanse of this disease in Brazil. The models were able to identify that a continuous process of environmental degradation favours the establishment of $L$. (N.) whitmani and the occurrence of ACL by a strong association of the vector(s) and ACL to areas of intermediate vegetation cover density.

Keywords: Climate change, Ecological niche modelling, Lutzomyia (N.) whitmani, Cutaneous leishmaniasis

\footnotetext{
* Correspondence: scosta@ioc.fiocruz.br

'Laboratório Interdisciplinar de Vigilância Entomológica em Diptera e

Hemiptera, Instituto Oswaldo Cruz, FIOCRUZ, Rio de Janeiro, Brasil

Full list of author information is available at the end of the article
} 


\section{Background}

The simplification of biological communities, the fragmentation and loss of habitats resulting from human occupation modify the parasite/host interactions, which may lead to the emergence and reemergence of several diseases in animal and human populations [1].

In the last decade, a growing number of studies have investigated the effects of biodiversity on the risk of disease occurrence, mainly due to the interest in identifying and evaluating the importance of biodiversity and the environmental services it provides [2]. The influence of diversity on transmission cycles has been described for some diseases [3, 4]. However, little is known about the ecological mechanisms related to these effects [5]. Understanding the structure and functioning of the ecological processes involved in the dynamics of the interactions between parasites, hosts, and the environment becomes critical to comprehend the relationship between biodiversity and the emergence or reemergence of zoonoses.

Due to new and complex epidemiological scenarios, leishmaniasis is considered a reemerging disease [6] modelling important public health problems in Brazil. American cutaneous leishmaniasis (ACL) represents an example of zoonosis related to land use and biodiversity management, both by the severity of the disease and by the direct relationship of elements and the environmental context (landscape) in its transmission cycle [7].

The circulation of phlebotomine sand fly vectors in environments outside the geographical limits of natural foci is increasing and leads to modifications in the classic epidemiological patterns of leishmaniasis. Such modifications are related to changes in the determinant factors for the exposure of man to transmission, demographic expansion and the process of urbanization on the limits of natural foci, as well as the occurrence of forest remnants adjacent to urban areas $[6,8,9]$.

In this context, we highlight $L$. (N.) whitmani, a sand fly species registered in 26 of 27 Brazilian federative units [10] and a transmitter of two dermotropic leishmaniasis species including Leishmania $(V$.) shawi in the Amazon, and Leishmania (V.) braziliensis in the North, Northeast, Midwest, Southeast and South Regions [11, 12]. The former presents different behaviour in different regions, has a wide geographical distribution, and is adapted to several climates and types of vegetation cover [10, 12, 13]. This ecological plasticity reflects the occurrence of this species in all epidemiological patterns described for ACL [9]. Throughout the Brazilian territory, according to qualitative changes related to antrophilia and domesticity, Lainson [14] suggested that $L$. (N.) whitmani represented a complex of cryptic species.

The characterization of factors influencing the spatial distribution of $L$. (N.) whitmani, in general, has been an efficient tool for a better understanding of ecological processes. The ecological niche models (ENM) has been widely used as a tool to describe environmental conditioning factors and to identify patterns related to environmental suitability for species occurrence $[15,16]$. In recent years, many techniques for modelling niches and species distributions have been developed and applied extensively in biogeography, ecology and conservation studies $[15,17,18]$. The maximum entropy model (MaxEnt) [19] is consistently competitive with the highest performing methods and is one of the most common approaches used to determine geographical distribution and ecological features of species $[20,21]$.

Peterson \& Shaw [22] modelled three sand fly vector species from South America, L. (N.) whitmani, Lutzomyia (Nyssomyia) intermedia and Lutzomyia migonei, and identified an increase in areas of climate suitability for the year 2050. According to the models, L. (N.) whitmani presented the greatest areas of dispersion. The purpose of the present study was to evaluate the environmental suitability and project future scenarios (via ENM), for L. (N.) whitmani and ACL in Brazil, in the face of global climate change.

\section{Methods \\ Occurrence data}

For data related to the occurrence of the disease, we used municipalities with records of endemic areas for ACL, based on the ACL Data Banks, for the period 2003 to 2013, provided by the Brazilian Ministry of Health ( $n=1882$, of which 1506 were used for modeling and 376 for additional accuracy test) (see Additional file 1: Table S1). For L. (N.) whitmani occurrence, the municipalities with a confirmed record of the vector $(n=992$, of which 794 were used for modelling and 198 for additional accuracy test), were considered in the $L$. (N.) whitmani model (see Additional file 2: Table S2).

Occurrence data for $L$. (N.) whitmani was extracted from previously published data (until 2013) available from online databases including PubMed (http://www.ncbi.nlm.nih.gov/ pubmed), the ISI Web of Knowledge (http://apps.webof knowledge.com), SCOPUS (http://www.scopus.com), and CAPES (http://catalogodeteses.capes.gov.br). We also collected unpublished records from the Health Department of Brazil and major Brazilian sand fly collections at the Centro de Pesquisas Rene Rachou, FIOCRUZ, the Instituto Evandro Chagas, IEC, and the Faculdade de Saude Publica, USP.

\section{Environmental descriptors}

Ten environmental variables $\left(0.04^{\circ}\right.$ of spatial resolution, $\sim 5 \mathrm{~km}$ ) were used, 8 of which were WorldClim [23] climatic variables, as well as data on altitude and vegetation indices, which are all displayed in Table 1. 
Table 1 Environmental variables used to model the potential distribution of Lutzomya (N.) whitmani and American cutaneous leishmaniasis in Brazil. All variables were resampled from original resolution to $0.04^{\circ}(\sim 5 \mathrm{~km})$, using the average value of all involved pixels, where the source pixels are covered by the target pixel

\begin{tabular}{|c|c|c|c|}
\hline Environmental variable & Acronym & WorldClim Acronym & Source \\
\hline Annual mean temperature & AMT & $\mathrm{BIO} 1$ & WorldClim [23] \\
\hline Mean temperature of wettest quarter & MTWEQ & $\mathrm{BIO} 8$ & \\
\hline Mean temperature of driest quarter & MTDQ & $\mathrm{BIO9}$ & \\
\hline Mean temperature of warmest quarter & MTWAQ & $\mathrm{BlO} 10$ & \\
\hline Mean temperature of coldest quarter & MTCQ & $\mathrm{BlO} 11$ & \\
\hline Annual precipitation & AP & $\mathrm{BlO} 12$ & \\
\hline Precipitation of wettest quarter & PWQ & $\mathrm{BIO16}$ & \\
\hline Precipitation of driest quarter & PDQ & $\mathrm{BIO17}$ & \\
\hline Altitude - digital elevation model & ALT & - & $\begin{array}{l}\text { Shuttle Radar Topography Mission } \\
\text { (http://www2.jpl.nasa.gov/srtm/) }\end{array}$ \\
\hline $\begin{array}{l}\text { MODIS normalized difference vegetation index- } 32 \text { day } \\
\text { composites-Oct/15 - Nov/15/2004. } \\
\text { Date of the composite represents well the contrast } \\
\text { between forest and open formations. }\end{array}$ & NDVI & - & $\begin{array}{l}\text { Global land cover facility } \\
\text { (http://www.landcover.org/data/modis/) }\end{array}$ \\
\hline
\end{tabular}

To project future environmental conditions (i.e. 2050), we used two representative concentration pathways (RCPs) of the HadGEM2-ESgeneral circulation model: RCP 4.5 and RCP 8.5 greenhouse gas concentration trajectories adopted by Intergovernmental Panel on Climate Change (IPCC) for its fifth Assessment Report (AR5) in 2014 [24]. These were selected to represent contrasting scenarios in projections for climate change. RCP 4.5 represents a relatively optimistic scenario and assumes that the radiative forcing of greenhouse gas stabilizes shortly after 2100 , and RCP 8.5 , more pessimistic, radiative forcing keeps rising after 2100.

\section{Ecological niche models}

We used the maximum entropy niche modelling approach, as implemented in MaxEnt software (version 3.3.3k), to evaluate the environmental suitability for $L$. (N.) whitmani and occurrence of ACL in Brazil, as well as to model projections for future climate change scenarios. The method considers the occurrence of $L$. (N.) whitmani in association with environmental variables [25], producing response curves that indicate how each variable affects the predicted distribution [26]. MaxEnt has been shown to be robust for ENM construction from presence-only data [24] and to describe the ecological and spatial relationships between species and environmental conditions.

MaxEnt was applied under the 'auto-features' mode, and the default settings, with 100-fold replicates generated by bootstrap [26]. The logistic output was used (habitat suitability on a scale of $0-1$ ), with higher values in the habitat suitability map (HSM) representing more favourable conditions for the occurrence of $L$. (N.) whitmani or ACL. Two models were developed: (i) the Lutzomyia
(N.) whitmani model (LWM), and (ii) American cutaneous leishmaniasis model (ACLM). Both models were developed using ten environmental variables, $80 \%$ of occurrence data for training and $20 \%$ for the test.

To infer the effect of climate change on the distribution of $L$. (N.) whitmani and ACL, each model was projected using the scenarios RCP 4.5 and RCP 8.5. For these projections, NDVI was removed, since this environmental variable had no projection for the future scenarios we used.

We assessed the accuracy of each model using AUC (area under the receiver operating characteristic [ROC] curve) on MaxEnt. Additionally, we used an independent set of 127 and 376 actual occurrence records, for $L$. (N.) whitmani and ACL human cases, respectively (randomly selected from total points and not used in the generation of models), to evaluate the predictive capacity of the models. The predicted suitability of the models was extracted for each test point using the ArcGIS 10.1 software (ESRIC), and the average suitability was used to evaluate model accuracy.

For L. (N.) whitmani and ACL, potential distribution binary maps (suitable/unsuitable) were applied the minimum training presence (MTP) as a threshold value for models, because it is the most conservative threshold, identifying the minimum predicted area possible while still maintaining a zero omission rate for both training and test data.

For comparative purposes, the images resulting from each model (with continuous values from 0 to 1 ) were reclassified into five environmental suitability zones: (i) unsuitable zone (UNSZ; value pixel suitability < minimum training presence, MTP); (ii) low suitability zone (LSZ, 
value pixel suitability between MTP value and 0.25); (iii) intermediate suitability zone (ISZ, value pixel suitability between 0.25 and 0.50); (iv) high suitability zone (HSZ, value pixel suitability 0.50 and 0.75 ); and (v) a very high suitability zone (VHSZ, value pixel suitability > 0.75 ).

\section{Model comparison}

The ACLM and LWM were compared using Fuzzy for continuous maps, and the Kappa index for categorical maps (suitable/unsuitable) using the Map Comparison Kit v.3.2 software developed by the Netherlands Environmental Assessment Agency [27, 28]. Both indices express the pixel similarity for a value between 0 (fully distinct) and 1 (fully identical).

Additionally, we used Olson et al.'s [29] delineation of the terrestrial "Ecoregions of the World" and the Brazilian biomes [30] as a base map to better demonstrate the comparison between generated.

\section{Results}

With an average AUC of 0.77 (SD $=0.004 ; 100$-fold replicates), ACLM achieved a satisfactory model fit, and the modelled distribution performed better than random. The predictive capacity of ACLM, evaluated by the average suitability test of $0.53(\mathrm{SD}=0.12)$ in each test point, indicates that the model achieved high accuracy. This average value corresponds to the high suitability zone for ACL. Based on the minimum training presence $(\mathrm{MTP}=0.07)$ cut off criteria $(\mathrm{MTP}=0.07)$, ACLM identified many of the regions of Brazil appropriate for the occurrence of ACLM (Fig. 1), covering $82.3 \%$ of the Brazilian territory. LWM showed similar performance, with a mean AUC of 0.82 (SD $=0.006 ; 100$-fold replicates) and average suitability test of $0.54(\mathrm{SD}=0.15)$, indicating the satisfactory predictive capacity of both models (Fig. 1), covering $83.4 \%$ of the Brazilian territory.

The vegetation density index (NDVI) was the variable with the highest gain in the model when it was omitted


Fig. 1 Occurrence data for American cutaneous leishmaniasis (ACL) and Lutzomyia (N.) whitmani (LW), and environmental suitability for ACL and LW in Brazil, current conditions. Unsuitable zone (UNSZ; value pixel suitability < minimum training presence, MTP), low suitability zone (LSZ, value pixel suitability between MTP value and 0.25 ), intermediate suitability zone (ISZ, value pixel suitability between $0.25-0.50$ ), high suitability zone (HSZ, value pixel suitability between $0.50-0.75$ ), and a very high suitability zone (VHSZ, value pixel suitability > 0.75) identified 
or used alone, causing the significance of ACLM to decrease, respectively. The response curves for Environmental variables $(\mathrm{EV})$ of this model indicate that $\mathrm{ACL}$ is strongly associated with intermediate density vegetation areas, zones with annual precipitation (AP) between $800-1200 \mathrm{~mm}$, mean temperature of coldest quarter (MTCQ) above $16{ }^{\circ} \mathrm{C}$, and annual mean temperature (AMT) lower than $23{ }^{\circ} \mathrm{C}$ (suitability of occurrence $>0.5$ ) (Figs. 2a and 3a).

Lutzomyia (N.) whitmani was identified by LWM as a species that "preferentially occurs" in regions with relative moderate rainfall (AP between $1000-1600 \mathrm{~mm}$ ), intermediate NDVI, and regions with MTCQ between 15$22{ }^{\circ} \mathrm{C}$ and AMT between $19-24{ }^{\circ} \mathrm{C}$ (Figs. $2 \mathrm{~b}$ and $3 \mathrm{a}$ ).

Figure 4 shows the future predicted distributions for ACL and L. (N.) whitmani in 2050, under both RCP 4.5 and RCP 8.5 (HadGEM2-ES model) for future climate scenarios. For ACL, these two projections differ moderately from current scenario (Fuzzy of 0.58 and 0.59 for RCP 4.5 and RCP 8.5 , respectively) and are very similar to each other (Fuzzy of 0.75 ). Similar results were found
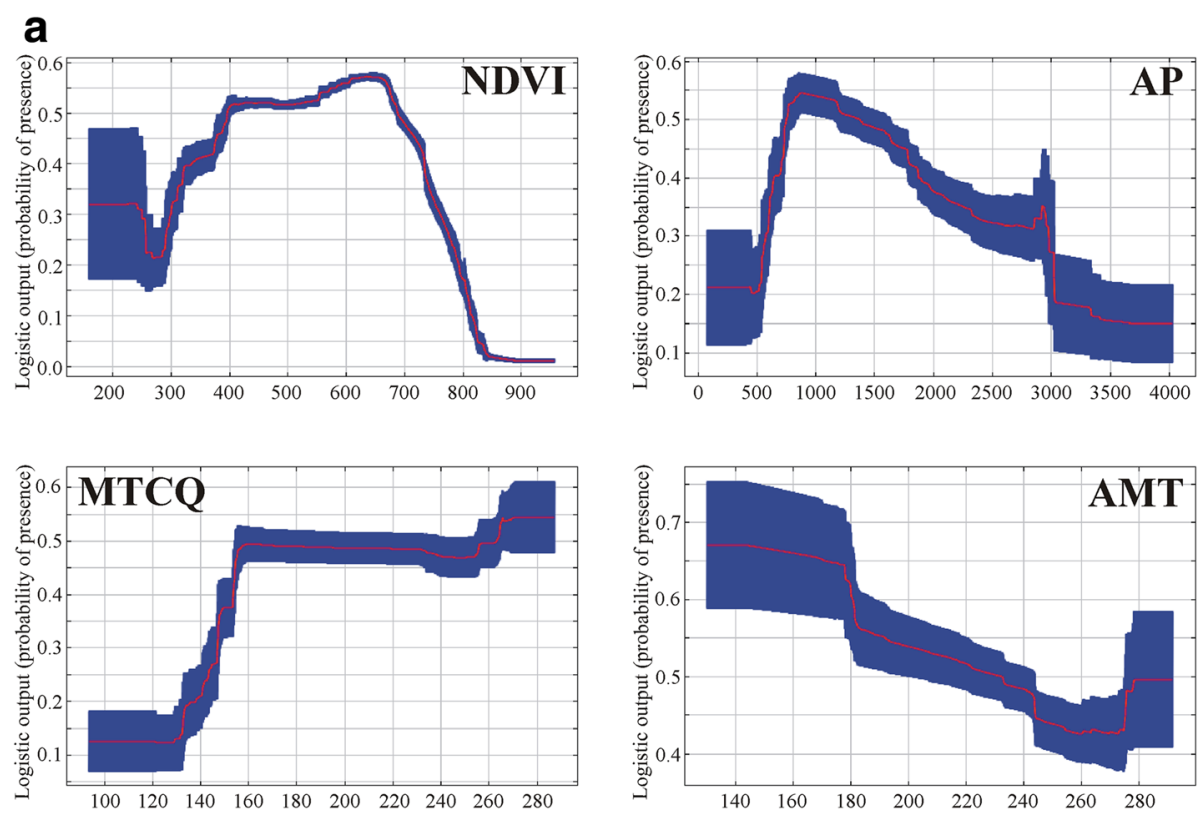

b
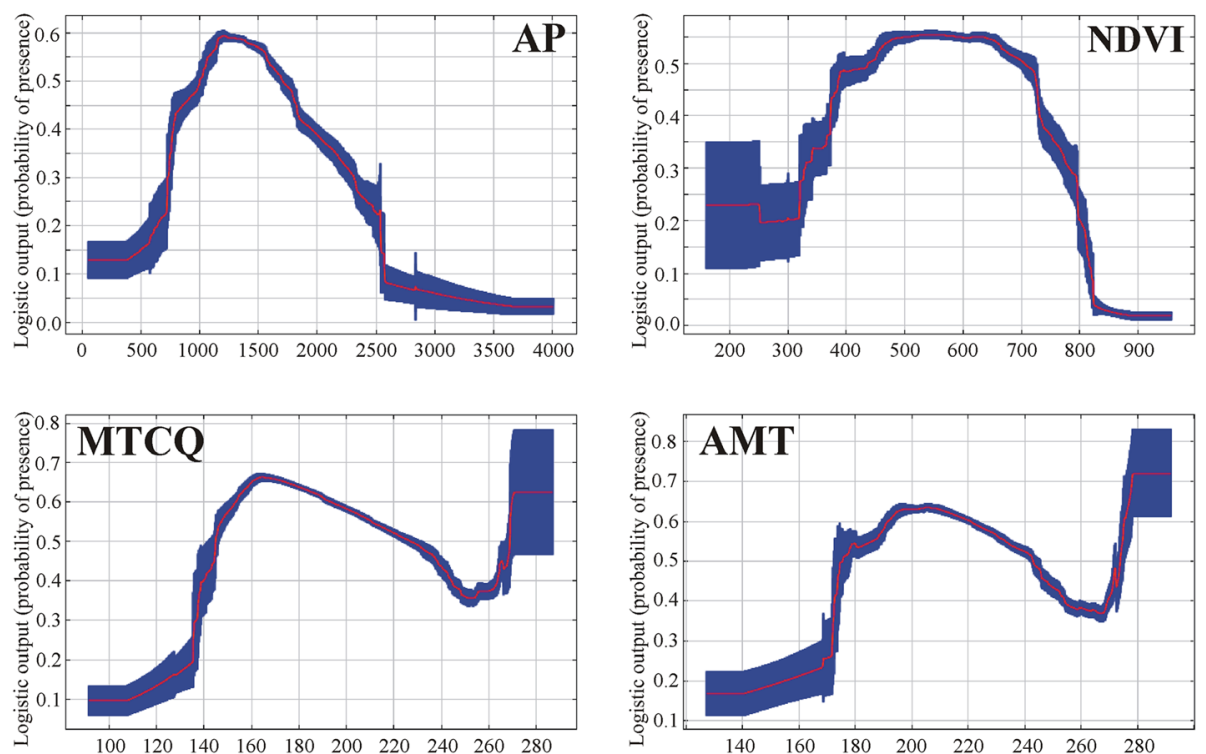

Fig. 2 Response-curves of the variables. a American cutaneous leishmaniasis model (ACLM). b Lutzomyia (N.) whitmani model (LWM). Normalized difference vegetation index (NDVI), annual precipitation (AP, BIO12), mean temperature of coldest quarter (MTCQ, BIO11), annual mean temperature (AMT, BIO1). These curves show how each environmental variable affects the MaxEnt prediction when all environmental variables are used to build the model 

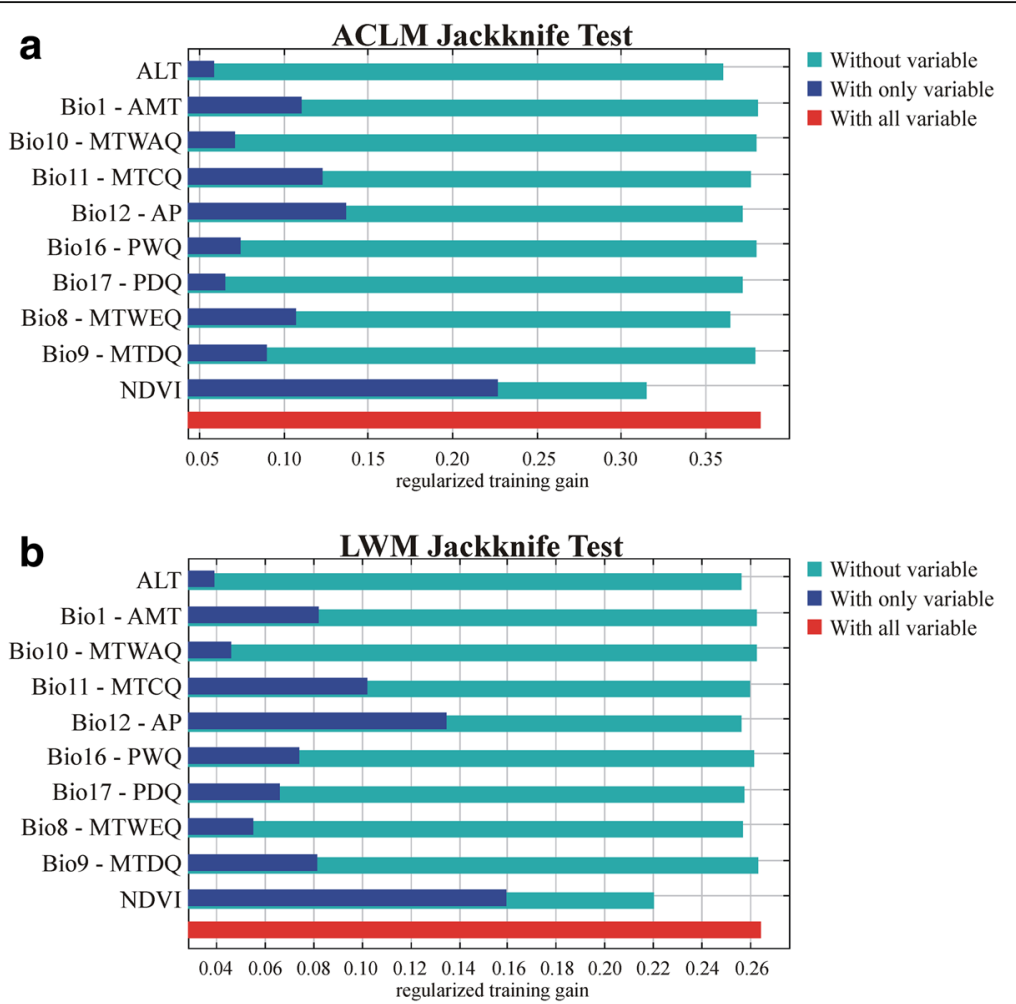

Fig. 3 Jackknife test results of individual environmental variable importance in the development of the MaxEnt models. a American cutaneous leishmaniasis model (ACLM). b Lutzomyia (N.) whitmani model (LWM) jackknife test results. Red bars represent results for all environmental variables; dark blue bars represent results for each predictor variable alone, and light blue bars represent the drop in training gain when the variable is removed from the full model

in the projections for L. (N.) whitmani (Fig. 4), but with greater similarity (Fuzzy of 0.74 and 0.64 , for current model versus RCP 4.5 and RCP 8.5 , respectively, and Fuzzy of 0.77 between future climate scenarios).

Comparisons between the models for ACL and $L$. (N.) whitmani indicate high similarity. Fuzzy of 0.77 between current models, and 0.77 and 0.78 for RCP 4.5 and RCP 8.5 scenarios, respectively.

All the projections indicate expansion of the $L$. $(N$.) whitmani occurrence areas in the Brazilian territory. It increases by $5 \%$ in RCP 4.5 scenario and $7.6 \%$ in RCP 8.5 scenario. For ACL, the area gain values were higher (12.3\% and $15.5 \%$ area gain for RCP 4.5 and RCP 8.5 , respectively).

Suitable areas (above MTP cutoff values) for $L$. (N.) whitmani are more extensive than those suitable for ACL. Such areas cover 7,113,644.7 $\mathrm{km}^{2}$ of Brazilian territory, $1.2 \%$ more than the suitability for ACL $\left(7,025,688.6 \mathrm{~km}^{2}\right)$. In future projections, this behaviour is repeated, but with higher gain values in the suitable area for this vector $(8.8 \%$ and $9.1 \%$ for RCP 4.5 and RCP 8.5, respectively).

Figure 5 shows the most dissimilar variables (MoD) between current and future climate scenarios. The MoD for a point $P$ is the variable concerning which $P$ has the smallest value of similarity, i.e. the variable driving the dissimilarity result [31]. For ACL and $L$. (N.) whitmani, the mean temperature of warmest quarter (MTWAQ), mean temperature of coldest quarter (MTCQ) and annual mean temperature (AMT) were the drivers of current/ future dissimilarity.

\section{Discussion}

The models generated for L. (N.) whitmani and ACL indicated a satisfactory predictive capacity. Future projections of LWM indicated a larger area of climatic suitability expansion for $L$. (N.) whitmani for northern Brazil and reinforces the expansion trend towards the South, as described by Peterson \& Shaw [22].

Lutzomyia $(N$.) whitmani can "adapt" to environmental changes, new ecological niches, tolerating and overcoming the effects of changes that constantly occur in natural environments [22, 32]. According to Peterson \& Shaw [22], L. (N.) whitmani, L. (N.) intermedia and $L$. migonei, phlebotomine vectors of ACL widely distributed in South America, by 2050 will have their climatic suitability areas increased. These species are expanding to different areas of the continent, with Peterson \& Shaw [22], identifying the southern direction as the most evident for $L$. (N.) whitmani, replacing areas previously occupied by 

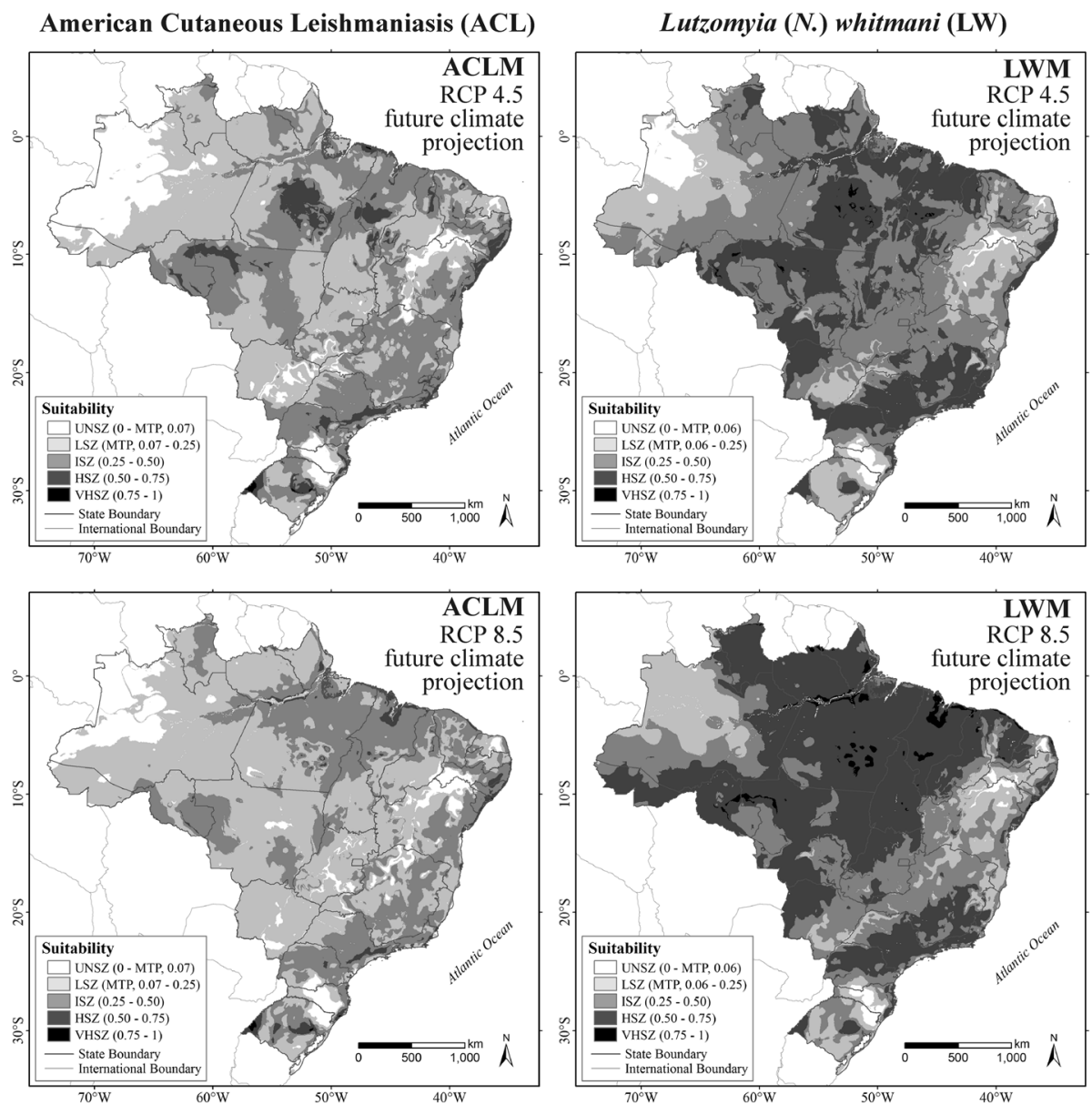

Fig. 4 Future climate projections for American cutaneous leishmaniasis (ACL) and Lutzomyia (N.) whitmani (LW). Unsuitable zone (UNSZ; value pixel suitability < minimum training presence, MTP), low suitability zone (LSZ, value pixel suitability between MTP value and 0.25 ), intermediate suitability zone (ISZ, value pixel suitability between $0.25-0.50$ ), high suitability zone (HSZ, value pixel suitability between $0.50-0.75$ ), and a very high suitability zone (VHSZ, value pixel suitability > 0.75) identified

L. (N.) intermedia (s.l.) [22]. Our results corroborate that study. However, when we add 12 years to the $L$. (N.) whitmani occurrence records used by Peterson \& Shaw [22] (a dataset before 2001), our current model shows the expansion predicted therein.

McIntyre et al. [33] contradicted Peterson \& Saw [22], stating that $L$. (N.) whitmani overlaps with $L$. (N.) intermedia only in southeastern Brazil. In fact, our models indicate that $L .(N$.) whitmani can replace $L .(N$.) intermedia in the southeastern region of Brazil, participating in ACL transmission cycle, mainly in the states of Espírito Santo, Minas Gerais, Rio de Janeiro, and São Paulo, sharing in the transmission of $L$. (V.) braziliensis, as previously described by $[34,35]$. As such, the expansion trend toward the south presented by our model represents the current distribution of Lutzomyia (Nyssomyia) neivai.

Other vectors of ACL present projections of future displacements towards higher latitudes, as observed in sand flies from Central and North America [36, 37].
Phlebotomus ariasi showed increased abundance at higher latitudes in central Spain. According to Gálvez et al. [38], the species would be migrating to these areas to compensate for the increase in temperatures in the region. Carvalho et al. [39] describe an expansion of Lutzomyia (Nyssomyia) flaviscutellata to the south and southeast of Brazil in the face of future climatic scenarios. Therefore, one can infer that the area of overlap between $L$. (N.) flaviscutellata and $L$. (N.) whitmani will be larger and more evident in the future.

The results point to the predicted expansion of $L$. (N.) whitmani in the northern region, especially the State of Amazonas: although future projections show that the Amazon region will become drier, as a consequence of the increase in intensity and duration of the dry season [40], $L$. (N.) whitmani remains present in the region and will have a more extensive climatic suitability area in the future. Considering the extensive latitudinal range of Brazil, regional climates play an important role in the 


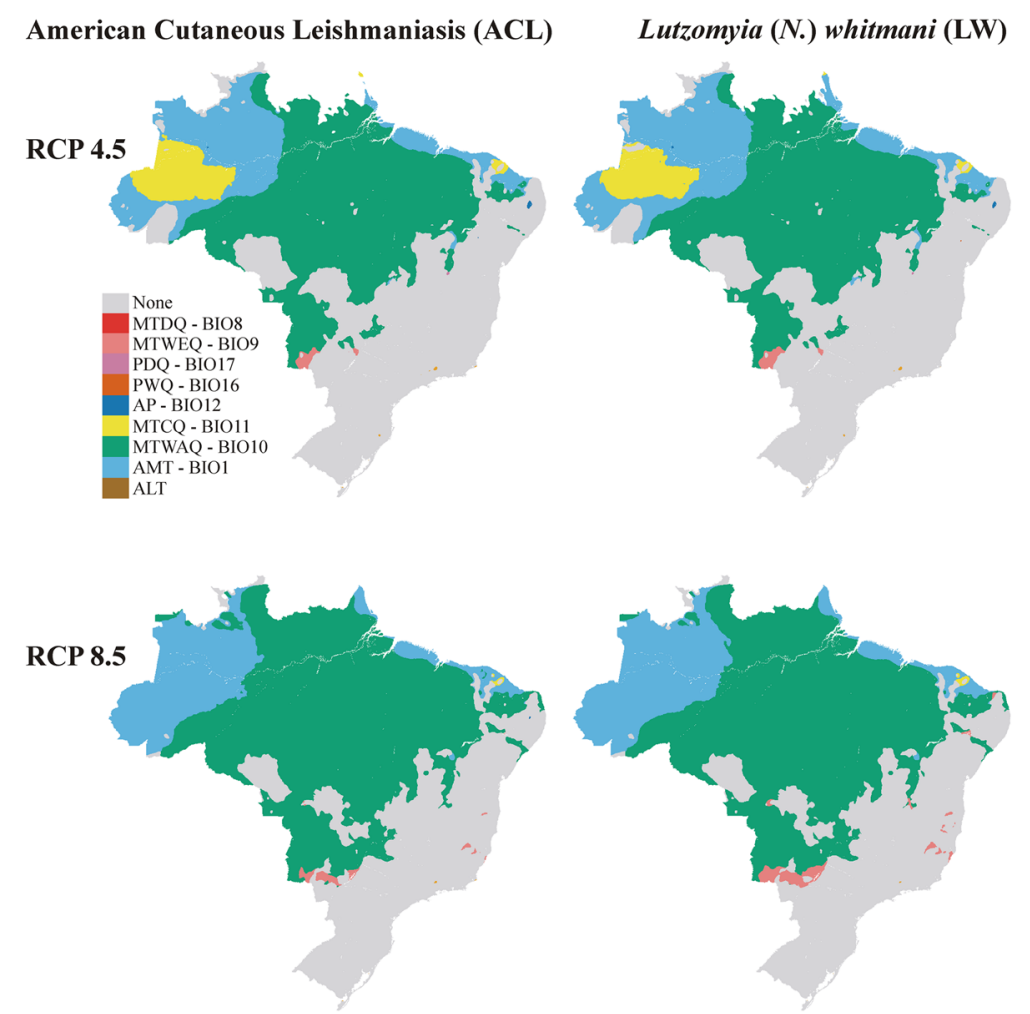

Fig. 5 The most dissimilar variables (MoD) between current and future climate scenarios. For $A C L$ and $L$. (N.) whitmani the mean temperature of warmest quarter (MTWAQ), mean temperature of coldest quarter (MTCQ) and annual mean temperature (AMT) were the drivers of current/future dissimilarity. Acronyms for environmental variables are provided in Table 1

definition of species distribution. According to Carvalho et al. [39], most projections of climate change endorse that vectors of diseases will find good climatic conditions for their geographical expansion in the higher latitudes during the coming decades.

In relation to the epidemiology of ACL in Brazil, the disease expansion process is related to environmental changes with new human cases being registered in areas of recent deforestation, mining, hydroelectric plant construction and population settlements $[9,12]$. These changes in the transmission pattern favour the dispersion of wild animals and sand flies mainly to the peridomestic environment, where new transmission cycles can be established close to houses [9]. In this case, L. (N.) whitmani and $L$. (N.) flaviscutellata would be particularly good examples of species, in different epidemiological situations [31]. This relationship is identified in ACLM by the strong relation of the most suitable areas for ACL with areas of intermediate vegetation cover density. Therefore, the most conserved Amazonian areas are identified as unsuitable.

Future projections for ACL indicate an expansion to northwestern Brazil. This is more evident in RCP 8.5, which is more pessimistic in relation to policies to control the emission of greenhouse gases, adding $15.5 \%$ to the total area of occurrence of the disease. The lack of future scenarios of the change in density and vegetation cover, in the way of those that exist for climatic data, made it impossible to quantify the role of changes in forest cover in future forecasts. However, the known and progressive environmental degradation, associated with future climate predictions that indicate that the Amazon region will tend to become more suitable climatically for both ACL and $L$. (N.) whitmani, design a scenario of higher risk of cases of disease $[39,41]$.

The larger distribution predicted in the models for $L$. (N.) whitmani regarding ACL epidemiology is possibly related to the sole presence of the vector not being deterministic for the disease. Other factors influence pathogen transmission as well as the development of the disease. The ecoepidemiology of Brazilian ACL is a complex of epidemiological chains involving different parasites, vectors, and reservoirs. The transmission of the seven Leishmania spp., associated with ACL in Brazil involves different phlebotomine species that are closely associated with the parasite's mammalian reservoirs (which range from xenathra to rodents to primates), resulting in a variety of transmission cycles in the different geographical regions in the country. However, the little difference between the areas identified as adequate for $L$. (N.) whitmani and ACL, associated with the high similarities between the models 
reinforce the geographical importance of this vector in the transmission of ACL.

\section{Conclusions}

The models showed that continuous process of environmental degradation favours the establishment of $L$. (N.) whitmani and the occurrence of ACL. Future projections of ACL models indicate the ongoing process of disease expansion in the face of the predicted climatic changes and reinforce the broad geographical expanse of the disease. In this view and associated with the new epidemiological patterns resulting from the drastic environmental changes (coupled with the presence of highly adapted vectors, reservoirs, and parasites) the epidemiological scenario for ACL indicates a continuous increasing of human cases. The results presented here are expected to improve assessment of vector surveillance actions, consequently contributing to the promotion of health in risk areas for ACL associated to L. (N.) whitmani, projected for future scenarios in Brazil.

\section{Additional files}

Additional file 1: Table S1. Compiled presence records of American cutaneus leishmaniasis (ACL). (XLSX $113 \mathrm{~kb}$ )

Additional file 2: Table S2. Compiled presence records of Lutzomyia (N.) whitmani. (XLSX $60 \mathrm{~kb}$ )

\section{Abbreviations \\ ACL: American cutaneous leishmaniasis; ACLM: American cutaneous leishmaniasis model; AMT: annual mean temperature; AP: annual precipitation; AR5: Fifth assessment report of the 2014 Intergovernmental Panel on Climate Change; ENM: ecological niche modelling; EV: environmental variables; HSM: habitat suitability map; IPCC: Intergovernmental Panel on Climate Change; LWM: Lutzomyia (N.) whitmani model; MaxEnt: Maximun entropy; MoD: most dissimilar variable; MTCQ: mean temperature of coldest quarter; MTP: minimum training presence; NDVI: Normalized Difference Vegetation Index; RCP: representative concentration pathway}

\section{Acknowledgments}

To the Foundation for Research Support of the State of Rio de Janeiro (Fundação de Amparo à Pesquisa do Estado do Rio de Janeiro, FAPERJ) for its support in the Climate Change Project and the State Health Secretariats for making the occurrence data of L. (N.) whitmani available.

\section{Funding}

FAPERJ grant E-26/111.618/2011.

\section{Availability of data and materials}

The data supporting the conclusions of this article are available within the article and its Additional files 1 and 2 .

\section{Authors' contributions}

SMdC collected the data. JLPC and EFR performed the statistical analyses. The three authors wrote the text, read and approved the final manuscript.

\section{Ethics approval and consent to participate}

Not applicable.

\section{Consent for publication}

Not applicable.

\section{Competing interests}

The authors declare that they have no competing interests.

\section{Publisher's Note}

Springer Nature remains neutral with regard to jurisdictional claims in published maps and institutional affiliations.

\section{Author details}

${ }^{1}$ Laboratório Interdisciplinar de Vigilância Entomológica em Diptera e Hemiptera, Instituto Oswaldo Cruz, FIOCRUZ, Rio de Janeiro, Brasil. ${ }^{2}$ Fiocruz da Mata Atlântica, Fundação Oswaldo Cruz, FIOCRUZ, Rio de Janeiro, Brasil.

Received: 15 August 2017 Accepted: 23 February 2018

Published online: 07 March 2018

\section{References}

1. Begon M, Harper JL, Townsend CR. Ecology: Individuals, Populations and Communities. Oxford: Blackwell Scientific Publications; 1990.

2. Loreau M, Naeem S, Inchausti P, Bengtsson J, Grime JP, Hector A, et al. Biodiversity and ecosystem functioning: current knowledge and future challenges. Science. 2001;294(5543):804-8

3. Van Buskirk J, Ostfeld RS. Controlling Lyme disease by modifying the density and species composition of tick hosts. Ecol Appl. 1995;5:1133-40.

4. Vaz PT, Rezende NGAM, Wanderley Filho JR, Travassos WAS. Bacia do Parnaíba. B Geoci Petrobras. 2007;15(2):289-97.

5. Keesing F, Holt RD, Ostfeld RS. Effects of species diversity on disease risk. Ecol Lett. 2006;9(4):485-98.

6. WHO. World Health Organization. Control of the leishmaniases: report of a meeting of the WHO Expert Committee on the Control of Leishmaniases, Geneva, 22-26 March 2010. WHO Technical Report Series, n949. Geneva: WHO Press; 2010.

7. Fonseca ES, D'Andrea LA Z, Taniguchi HH, Hiramoto RM, Tolezano JE, Guimarães RB. Spatial epidemiology of American cutaneous leishmaniasis in a municipality of West São Paulo State, Brazil. J Vector Borne Dis. 2014;51(4):271-5.

8. Lainson R, Rangel EF. Lutzomyia longipalpis and the eco-epidemiology of American visceral leishmaniasis, with particular reference to Brazil: a review. Mem Inst Oswaldo Cruz. 2005;100(8):811-27.

9. Brasil MS/SVS - Ministério da Saúde/Secretaria de Vigilância em Saúde/ Departamento de Vigilância Epidemiológica. Manual de Vigilância da Leishmaniose Tegumentar Americana. 2a ed. Brasília: Editora do Ministério da Saúde; 2013.

10. Costa SM, Cechinel M, Bandeira V, Zannuncio JC, Lainson R, Rangel EF. Lutzomyia (Nyssomyia) whitmani s.l. (Antunes \& Coutinho, 1939) (Diptera: Psychodidae: Phlebotominae): geographical distribution and the epidemiology of American cutaneous leishmaniasis in Brazil - mini-review. Mem Inst Oswaldo Cruz. 2007;102(2):149-53.

11. Lainson R, Shaw JJ. New World Leishmaniasis. In: Collier L, Balows A, Sussman M, editors. Topley \& Wilson's Microbiology and Microbial Infections. 10th ed. London: E Arnold; 2005. p. 313-49.

12. Rangel EF, Lainson R. Proven and putative vectors of American cutaneous leishmaniasis in Brazil: aspects of their biology and vectorial competence. Mem Inst Oswaldo Cruz. 2009;104(7):937-54.

13. Rangel EF, Lainson R. Ecologia das leishmanioses: transmissores de leishmaniose tegumentar americana. In: Rangel EF, Lainson R, editors. Flebotomíneos do Brasil. Rio de Janeiro: Fiocruz; 2003. p. 291-310.

14. Lainson R. Ecological interactions in the transmission of the leishmaniasis. Philos Trans R Soc Lond B. 1988;321:389-404.

15. Guisan A, Zimmermann EE. Predictive habitat distribution models in ecology. Ecol Model. 2000;135:147-86.

16. Peterson AT, Soberón J, Pearson RG, Anderson RP, Martínez-Meyer E, Nakamura $\mathrm{M}$, et al. Ecological niches and geographic distributions. Monographs in Population Biology 49. New Jersey: Princeton University Press; 2011.

17. Guisan A, Thuiller W. Predicting species distribution: offering more than simple habitat models. Ecol Lett. 2005:8:993-1009.

18. Elith J, Leathwick JR. Species distribution models: Ecological explanation and prediction across space and time. Ecology. 2009:40:677-97.

19. Elith J, Graham CH, Anderson RP, Dudík M, Ferrier S, Guisan A, et al. Novel methods improve prediction of species' distributions from occurrence data. Ecography. 2006;29:129-51. 
20. Elith J, Phillips SJ, Hastie T, Dudik M, Chee YE, Yates CJA. statistical explanation of MaxEnt for ecologists. Divers Distrib. 2011;17:43-7.

21. Rodríguez-Soto C, Monroy-Vilchis O, Maiorano L, Boitani L, Faller JC, Briones MÁ, et al. Predicting potential distribution of the jaguar (Panthera onca) in Mexico: identification of priority areas for conservation. Divers Distrib. 2011; 17(2):350-61.

22. Peterson A, Shaw J. Lutzomyia vectors for cutaneous leishmaniasis in southern Brazil: ecological niche models, predicted geographic distributions, and climate change effects. Int J Parasitol. 2003;33(9):919-31.

23. Hijmans $R$, Cameron $S$, Parra J, Jones $P$, Jarvis A. Very high resolution interpolated climate surfaces for global land areas. Int J Climatol. 2005, 25(15):1965-78.

24. IPCC. Summary for Policymakers. In: Stocker TF, Qin D, Plattner GK, Tignor M, Allen SK, Boschung J, Nauels A, Xia Y, Bex V, Midgley PM, editors. Climate Change 2013: The Physical Science Basis Contribution of Working Group I to the Fifth Assessment Report of the Intergovernmental Panel on Climate Change. New York, USA, Cambridge, UK: Cambridge University Press (CUP); 2013. p. 1-30

25. Phillips SJ, Anderson RP, Schapire RE. Maximum entropy modelling of species geographic distributions. Ecol Model. 2006;190:231-59.

26. Phillips SJ, Dudík M. Modeling of species distributions with Maxent: new extensions and a comprehensive evaluation. Ecography. 2008;31:161-75.

27. Visser H, Nijs T. The Map Comparison Kit. Environ Model Softw. 2006;21:346-58.

28. Hagen-Zanker A, Straatman B, Uljee I. Further developments of a fuzzy set map comparison approach. Int J Geogr Inf Sci. 2005;19:769-85.

29. Olson DM, Dinerstein E, Wikramanayake ED, Burgess ND, Powell GVN, Underwood EC, et al. Terrestrial ecoregions of the World: a new map of life on Earth. Bioscience. 2001;51:933-8.

30. IBGE. Mapa de Biomas do Brasil, primeira aproximação, Rio de Janeiro. 2014. https://ww2.ibge.gov.br. Accessed 16 Nov 2016.

31. Falqueto A. Especificidade alimentar de flebotomíneos em duas áreas endêmicas de leishmaniose tegumentar no estado do Espírito Santo, PhD Thesis, Fiocruz, Rio de Janeiro; 1995. p. 84.

32. Ready PD. Leishmaniasis emergence and climate change. Rev Sci Tech. 2008;27(2):399-412.

33. McIntyre S, Rangel EF, Ready PR, Carvalho BM. Species-specific ecological niche modelling predicts different range contractions for Lutzomyia intermedia and a related vector of Leishmania braziliensis following climate change in South America. Parasit Vectors. 2017;10:157.

34. Pessôa SB, Coutinho JO. Infecção natural e experimental dos flebótomos pela Leishmania braziliensis no estado de São Paulo. Hospitals. 1941;20:25-35.

35. Souza CM, Pessanha JE, Barata RA, Monteiro EM, Costa DC, Dias ES. Study on phlebotomine sand fly (Diptera: Psychodidae) fauna in Belo Horizonte, state of Minas Gerais, Brazil. Mem Inst Oswaldo Cruz. 2004:99:795-803.

36. González C, Wang O, Strutz SE, González-Salazar C, Sánchez-Cordero V Sarkar S. Climate change and risk of leishmaniasis in North America: predictions from ecological niche models of vector and reservoir species. PLos Neglect Trop Dis. 2010;4(1):e585.

37. Moo-Llanes $\mathrm{D}$, Ibarra-Cerdeña CN, Rebollar-Téllez EA, Ibáñez-Bernal S, González C, Ramsey JM. Current and future niche of North and Central American sand flies (Diptera: Psychodidae) in climate change scenarios. PLoS Negl Trop Dis. 2013;7(9):e2421.

38. Gálvez R, Miró G, Descalzo MA, Nieto J, Dado D, Martín O, et al. Emerging trends in the seroprevalence of canine leishmaniosis in the Madrid region (central Spain). Vet Parasitol. 2010;169:327-34.

39. Carvalho BM, Rangel EF, Ready PD, Vale MM. Ecological niche modelling predicts southward expansion of Lutzomyia (Nyssomyia) flaviscutellata (Diptera: Psychodidae: Phlebotominae), vector of Leishmania (Leishmania) amazonensis in South America, under climate change. PLoS One. 2015; 10(11):e0143282.

40. Passos VNA, Silva RE, Falcão AL. Fauna flebotomínica de municípios da região metropolitana de Belo Horizonte. Rev Soc Bras Med Trop. 1991; 24(Suppl. 11):107.

41. Rangel EF, Costa SM, Carvalho BM. Environmental changes and the geographic spreading of American cutaneous leishmaniasis. In: Claborn D, editor. Leishmaniasis trends in epidemiology, diagnosis and treatment. Croatia: InTech; 2014. p. 3-25.

\section{Submit your next manuscript to BioMed Central and we will help you at every step:}

- We accept pre-submission inquiries

- Our selector tool helps you to find the most relevant journal

- We provide round the clock customer support

- Convenient online submission

- Thorough peer review

- Inclusion in PubMed and all major indexing services

- Maximum visibility for your research

Submit your manuscript at www.biomedcentral.com/submit
Biomed Central 